J. Amer. Soc. Hort. Sci. 115(5):820-823. 1990.

\title{
Application of Plastochron Index to Common Bean Grown in Controlled Environments
}

\author{
K.S. Yourstone'and D.H. Wallace ${ }^{2}$ \\ Department of Plant Breeding and Biometry, Cornell University, Ithaca, NY 14853
}

Additional index words. plant development, photoperiod, temperature, leaf initiation, node development, shoot development, Phaseolus vulgaris

\begin{abstract}
This study was undertaken to determine whether plastochron index (PI), a mathematical construct that quantifies shoot development, can be applied to indeterminate bean (Phaseolus vulgaris L.) genotypes. Length measurements of the middle trifoliate leaflet were the basis of the PI calculation. The expansion of each middle trifoliate leaflet at every node on each plant tested was measured over time to determine whether the growth pattern of each leaflet fits the assumptions of the PI construct. Plants from five indeterminate bean genotypes were grown in two controlled environments: A constant $29 \mathrm{C}$ with 12-hr of daylength, and a constant $23 \mathrm{C}$ with 12-hr daylength extended to $14 \mathrm{hr}$ with low light intensity. Early leaflet expansion was exponential for all five genotypes in both environments. Expansion rates of successive leaflets were also similar, although a few leaflets in three of the 10 genotype-environment combinations differed in their rates of expansion. Exponential and equal rates of expansion validate the calculation of the fractional component of the PI. In both environments, all genotypes exhibited an increasing rate of leaf initiation with time, which precludes the use of a simple linear slope in estimating rate of development.
\end{abstract}

In bean, photoperiod has been shown to modify the node of flower, and temperature modifies both the node of flower and the rate of node development, resulting in a complex photoperiod $\times$ temperature interaction for time to anthesis (Wallace, 1985). A major need in studies of time to flower is separation of temperature effects on the node to first flower from the temperature effects on rate of node development. The latter could be quantified by determining the relationship between the number of developed plastochrons and time. The plastochron traditionally has been defined as the duration between initiation of successive leaf primordia on the main stem apex. The time required for successive leaves to reach a specified length is a nondestructive estimate of the plastochron. For example, Watson and Baptiste (1938) measured stage of development in sugar beet (Beta vulgaris L.) by counting the number of leaves $>2.5$ $\mathrm{cm}$ long. Erickson and Michelini (1957) enhanced this technique by describing a method for estimating the number of developed plastochrons plus the fractional component of the plastochron currently undergoing development. This calculation they termed plastochron index (PI). Lamoreaux et al. (1978) reviewed use of the PI in a wide variety of investigations.

Our objective was to determine if leaf growth and initiation patterns required by the PI construct existed in bean, preliminary to a study of daylength $\times$ temperature interaction effects on rate of node development (Yourstone and Wallace, 1990).

\section{Materials and Methods}

Five indeterminate bean genotypes (Table 1) were each grown in a 4.2 -liter plastic pot filled with a mixture of $40 \%$ peatmoss, $60 \%$ vermiculite and dolomitic lime, micronutrients, and $30 \mathrm{~g}$ of Osmocote (14N-14P-14K). Three seeds were sown in each

Received for publication 23 Dec. 1988. Part of a PhD dissertation by K.S.Y. Department of Plant Breeding and Biometry paper no. 771. This research was supported by Hatch Act project 487 and the USAID Title XII Bean/Cowpea CRSP. We gratefully acknowledge the assistance of B. Rich and the Cornell growth chamber personnel. The cost of publishing this paper was defrayed in part by the payment of page charges. Under postal regulations, this paper therefore must be hereby marked advertisement solely to indicate this fact.

'Former Graduate Research Assistant. Current address: Dept. of Vegetable Crops, Cornell University, Ithaca, NY 14853.

'Professor.
Table 1. All genotypes described are of indeterminate growth habit. Photoperiod sensitivity reflects delay to flowering in long daylength.

\begin{tabular}{llll}
\hline \hline \multicolumn{1}{c}{ Genotype } & \multicolumn{1}{c}{ Origin } & \multicolumn{1}{c}{$\begin{array}{c}\text { Growth } \\
\text { habit }\end{array}$} & $\begin{array}{c}\text { Photoperiod } \\
\text { sensitivity }\end{array}$ \\
\hline Jamapa & Mexico & Bush & Low \\
Magdalena-3 & Colombia & Climbing & Moderate \\
Porrillo Sintetico & El Salvador & Bush & Moderate \\
P326(PI 310740) & Guatemala & Climbing & Low \\
Rojo 70 & El Salvador & Climbing & High \\
\hline
\end{tabular}

pot. The seed coats were scarified before sowing to promote uniform germination. After emergence, the plants were thinned to one per pot. One plant was discarded to retain the four most uniform ones of each genotype. Axillary branch buds were removed as they developed in nodes along the main stem, thus forcing all vegetative growth and flower development to occur on the main stem. The plants were grown in two growth chambers set at different environments: 1 ) a constant of $23 \mathrm{C}$ with 12 $\mathrm{hr}$ of full light (50\% incandescent, $50 \%$ fluorescent) at $\approx 180$ $\mu \mathrm{mol} \cdot \mathrm{s}^{-1} \cdot \mathrm{m}^{-2}$ plus an additional $2 \mathrm{hr}$ of extended daylength at $25 \%$ full light, and 2) a constant of $29 \mathrm{C}$ with $12 \mathrm{hr}$ full light. This produced 10 genotype-environment combinations.

Handa and Yong Son (1974) determined that central leaflets of soybean (Glycine max) were easier to measure and produced less error than whole compound leaves. Therefore, three times a week, the middle leaflet of each trifoliate leaf was measured to the nearest $0.1 \mathrm{~mm}$ from the tip to the base of the lamina using a vernier caliper. Leaflets $>120 \mathrm{~mm}$ were beyond the caliper range and were measured to the nearest millimeter using a ruler. Measurements were terminated at anthesis.

The basis of the PI calculation is illustrated in Fig. 1. A reference length is selected and a plastochron is defined as the time interval (points $\mathrm{A}$ to $\mathrm{C}$ in Fig. 1) required for successive leaves to achieve the reference length. The developmental age is $n$ plastochrons when leaf $n$ is exactly the reference length, $n$ +1 plastochrons when leaf $n+1$ is the reference length, etc. Generally, no leaf will be exactly the reference length at the time of measurement. Therefore, a fractional component is calculated based on the geometric relationship of equality between the ratio of lines $\mathrm{DB}$ and $\mathrm{DE}$ and the ratio of lines $\mathrm{AB}$ and $\mathrm{AC}$ 


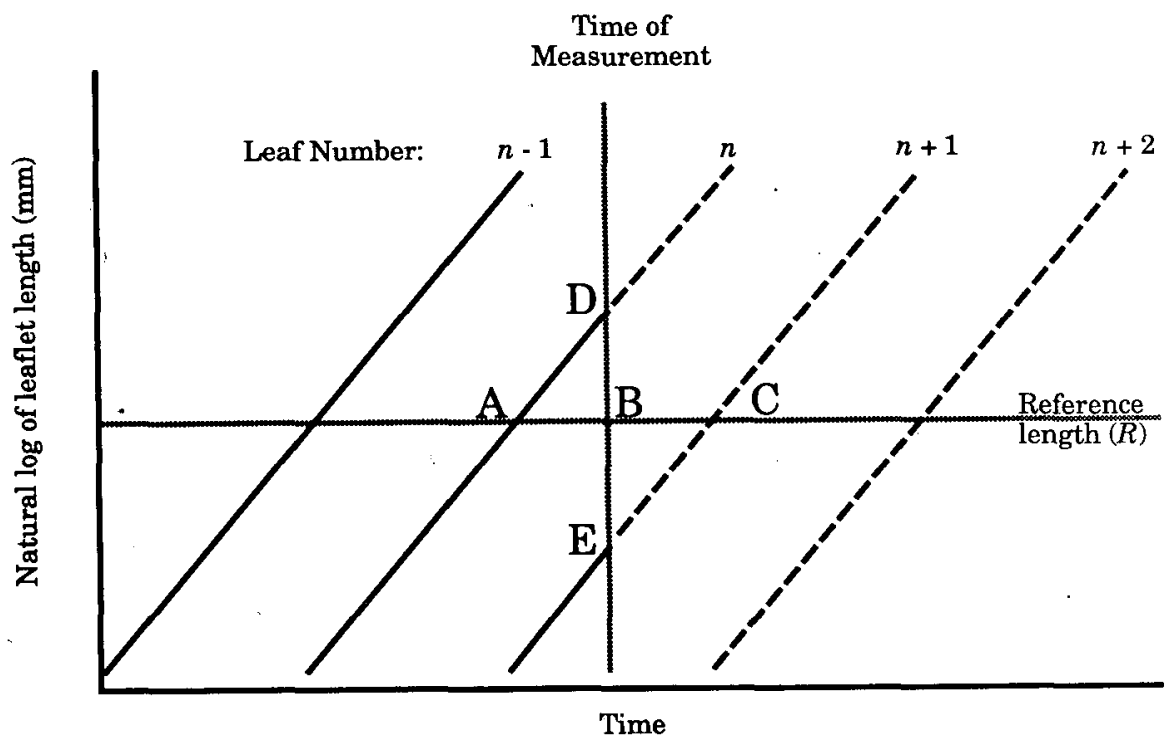

Fig. 1. Idealized representation of the natural logarithm of leaflet length over time. when lines $\mathrm{AD}$ and $\mathrm{EC}$ are parallel and linear. PI is expressed in terms of leaf length by the equation:

$$
\mathrm{PI}=\mathrm{n}+\frac{\ln \left(\mathrm{L}_{\mathrm{n}}\right)-\ln (\mathrm{R})}{\ln \left(\mathrm{L}_{\mathrm{n}}\right)-\ln \left(\mathrm{L}_{\mathrm{n}+1}\right)}
$$

where: $\mathrm{n}$ is the number of leaves longer than the reference length $(\mathrm{R})$, and $\mathrm{L}$ is the length of the middle trifoliate leaflet of leaf $\mathrm{n}$ or $\mathrm{n}+1$. The fractional component of Eq. [1] is the ratio of lines DB and DE (Fig. 1). To accurately estimate the fractional component of PI, early expansion growth of successive leaves must be exponential and of equal rates; i.e., the plot of $\ln$ (leaf length) vs. time must be linear and parallel for successive leaves.

For each of the 10 genotype-environment combinations, growth profiles of the natural logarithm of leaflet length of successive leaflets were generated. Each growth curve was the average of four leaflets from four separate plants. The profile for the genotype 'Jamapa' is shown in Fig. 2. From these profiles, the time period over which leaflet expansion was exponential was determined by noting the duration of a linear relationship between in (leaflet length) and days. Data beyond the period of exponential growth were not included in further analysis.

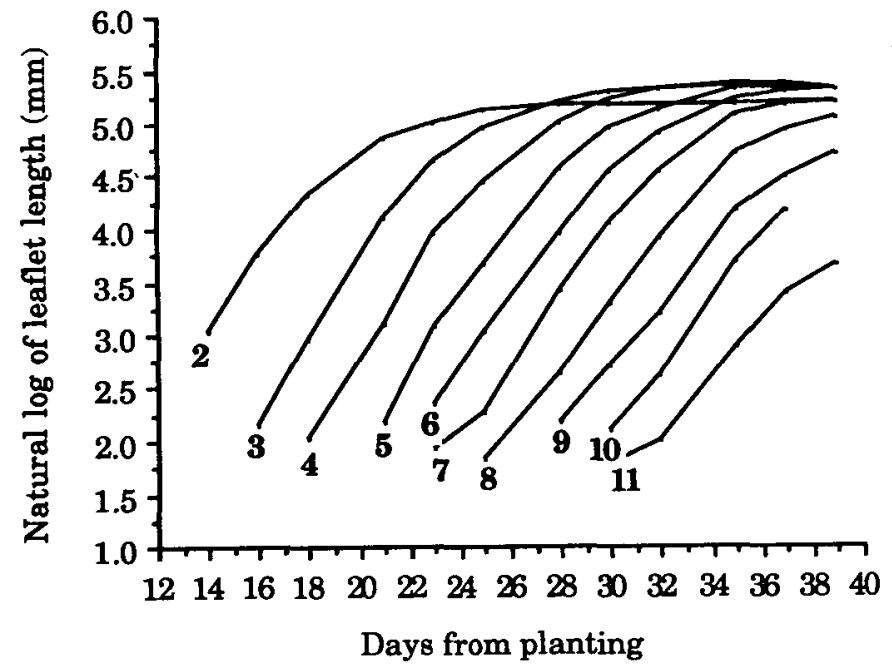

Fig. 2. An example of a leaflet profile from 'Jamapa' grown at $23 \mathrm{C}$ with $14 \mathrm{hr}$ of daylength. Leaves are numbered in order of appearance.
Testing of the rates of leaflet expansion for successive leaflets was performed using regression analysis for each leaflet of each of the 10 genotype-environment combinations according to the model $Y=\alpha_{i j}+\beta_{i j} T+\epsilon$, where $Y$ is ln (leaflet length) of the $i^{\text {th }}$ leaflet of the $j^{\text {th }}$ genotype-environment, $\mathrm{T}$ is time in days from planting, $\alpha_{i_{i j}}, \beta_{i j}$ are the intercept and slope regression coefficients of the $i^{\text {th }}$ leaflet and $j^{\text {th }}$ genotype-environment, and $\boldsymbol{\epsilon}_{\mathrm{iji}}$ is normally distributed random error of the $i^{\text {ih }}$ leaflet and $\mathrm{j}^{\text {th }}$ genotype-environment.

For each genotype-environment, the hypothesis of equal slopes (i.e. $H_{0}: \beta_{1}=\beta_{2}=\ldots=\beta_{\mathrm{ij}}$ ) was tested as described by Zar (1974). Analysis proceeded under the assumption that $\left.\sigma^{2} \mathbf{Y} \cdot \mathbf{X}\right)_{1 \mathrm{j}}=$ $\left(\sigma^{2} \cdot \mathrm{X}\right)_{2 \mathrm{j}}=\ldots=\left(\sigma^{2} \mathrm{Y} \cdot \mathrm{X}\right)$ :For genotype-environments with a significant difference between slopes, Newman-Keuls multiple range tests were employed to determine which slopes differed.

When the initiation of leaves occurs at equal time intervals, i.e., the plastochrons are of equal durations, then PI can serve as a direct measure of plant development. In this case, PI has a linear relationship with time with the slope being an estimate of the rate of node development and only two measurements in time are needed to estimate this slope. Regression analysis was employed to test whether leaf initiation rates remained constant for successive leaflets. Plastochron indices were calculated and these were regressed on time (days from planting). When plastochron intervals are constant, the relationship between PI and time is linear. Lack of fit of the linear model was tested using residual plots. The plastochron was defined as the time in days required for successive leaves to reach a reference length of $20 \mathrm{~mm}$.

\section{Results and Discussion}

Test of exponential growth. Profiles of the natural logarithms of leaflet length vs. time revealed linear relationships during early growth (Fig. 2) for each leaflet in each genotype-environment. For a given leaflet, measuring three times per week provided three to five measurements within the period of exponential growth. The average coefficients of determination $\left(r^{2}\right)$ from the regression of the logarithm of leaflet length on time over successive leaflets ranged from 0.76 to 0.97 (Table 2), indicating that the logarithmic transformation of leaflet lengths was linear over time and the early leaflet expansion was exponential. Low coefficients of determination resulted from individual leaflets showing unusual or delayed development, possibly 
Table 2. Mean coefficients of determination ( $r-z)$ over leaflets from the regression of the logarithm (base e) of leaflet length on days from planting and the common slope [logarithm (base e) of millimeters per day of leaflet expansion] for genotype-environments where statistical analysis showed-equal slopes.

\begin{tabular}{|c|c|c|c|c|}
\hline \multirow[b]{2}{*}{ Genotype } & \multicolumn{2}{|c|}{$29 \mathrm{C} / 12 \mathrm{hr}$ full light } & \multicolumn{2}{|c|}{$\begin{array}{l}23 \mathrm{C} / 12 \mathrm{hr} \text { full light } \\
\text { plus } 2 \mathrm{hr} 20 \% \text { full ligh }\end{array}$} \\
\hline & $r^{2}$ & $\begin{array}{l}\text { Common } \\
\text { slope }\end{array}$ & $r^{2}$ & $\begin{array}{c}\text { Common } \\
\text { slope }\end{array}$ \\
\hline Jamapa & 0.92 & 0.34 & 0.88 & 0.31 \\
\hline Magdalena* & 0.89 & $\mathrm{NA}^{\mathrm{z}}$ & 0.94 & NA \\
\hline Porr. Sint. & 0.88 & 0.30 & 0.97 & $\mathrm{NA}$ \\
\hline PI 310740 & 0.91 & 0.36 & 0.81 & 0.32 \\
\hline Rojo 70 & 0.82 & 0.25 & 0.76 & 0.26 \\
\hline
\end{tabular}

${ }^{2} \mathrm{NA}=$ Not applicable because individual leaflets had significantly differing $(P=0.05)$ rates of expansion in these treatments.

due to extensive handling of the leaflet while taking measurements.

Leaflets developing at $23 \mathrm{C}$ with $14 \mathrm{hr}$ of daylength did not slow below an exponential growth rate until they were $\approx 95 \mathrm{~mm}$ long, whereas leaflets developing at $29 \mathrm{C}$ with $12 \mathrm{hr}$ of daylength slowed in growth when they were $\approx 70 \mathrm{~mm}$ long. Final leaflet lengths were $\approx 30 \%$ greater at $23 \mathrm{C}$ plus $14 \mathrm{hr}$ of daylength than at $29 \mathrm{C}$ and $12 \mathrm{hr}$ of daylength. Final leaflet lengths increased progressively for the first two to four leaflets, as also reported for Lycopersicon esculentum (Coleman and Greyson, 1976) and Dianthus chinensis (McCauley and Croxdale, 1984).

The exponential growth phase for all five genotypes was shorter at $29 \mathrm{C}$ and $12 \mathrm{hr}$ of daylength than $23 \mathrm{C}$ with $14 \mathrm{hr}$ of daylength. Within the two environments, there was little variation for the duration of exponential growth among the five genotypes. Snyder and Bunce (1983) also reported environmental influence on the duration of exponential growth and final leaf lengths in soybean. The duration of exponential growth affects the selection of a suitable reference length ( $R$ in Eq. [1]). $R$ must be such that $\mathrm{L}_{\mathrm{n}}$ and $\mathrm{L}_{\mathrm{n}+1}$ are both within the period of exponential growth and are measurable. Because of modification of the exponential growth duration by environment, the selected $\mathrm{R}$ should be the smallest possible leaflet length of $n$ such that $L_{n+1}$ is also measurable. In practice, leaflets $<3$ or $4 \mathrm{~mm}$ long were impractical to measure. When $\mathrm{L}_{\mathrm{n}}$ was near $20 \mathrm{~mm}, \mathrm{~L}_{\mathrm{n}+1}$ fell within the range of 5 to $15 \mathrm{~mm}$. Therefore, $\ln (20 \mathrm{~mm})=3.0$ was selected as R.

Test of equal leaflet expansion rates. Leaflet expansion rates of successive leaflets were found to be equal for seven of the 10 genotype-environment combinations (Table 2). 'Magdalena' tested significant for different slopes in both environments and 'Porrillo Sintetico' tested significant at 23C with $14 \mathrm{hr}$ of daylength. For these three genotype-environment combinations that tested for unequal slopes, Newman-Keuls multiple range tests showed that, in actuality, only a few leaflets exhibited differences between slopes. In each of these three cases, the leaflet expansion rates were similar in the lower two-thirds of the plant. In the extended daylength environment, 'Magdalena' and 'Porrillo Sintetico' each had one leaflet (leaflets 16 and 9, respectively) that expanded at a significantly lower rate than several other leaflets below it. 'Magdalene', when grown in the 29C/ 12-hr full light environment, exhibited variable expansion rates of leaflets 13 to 16. This range contained both the fastest (leaflet 13) and slowest (leaflet 15) expanding leaflets. In all three cases, the significant test of differences between slopes was due to a relatively small number of leaflets that differed in expansion rate from a few other leaflets. In no case was there a leaflet that expanded faster or slower than all, or even most, of the other leaflets on the plant.

As plants become larger, it is not unreasonable to expect deviations in growth patterns. Additional variation could be the result of the simultaneous development of both the upper third of the plant and flower buds within this same region of the plant. Coleman and Greyson (1976) reported failure of the assumptions of PI on tomato shoots after the initiation of flower buds, based on the observation that PI did not retain a linear relationship with time after flower bud production began.

Test of equal plastochron duration. PI plotted against time (Fig. 3) indicated that early plastochrons were of longer durations than later plastochrons. Linear regressions of PI on time showed very high coefficients of determination for each genotype-environment combination, but, for each, the residuals (y - $\hat{y}$ ) plotted against time produced a U-shaped pattern, indicating a curvilinear rather than linear relationship. Regressions were recalculated including a quadratic term for time in the model. The quadratic term was (days from planting minus 30$)^{2}$. Thirty was near the overall mean for days from planting and was subtracted to reduce correlation between the linear and quadratic terms (Snedecor and Cochran, 1980) of the model: PI = $\beta_{1}+\beta_{2}$ DFP $+\beta_{3}(\text { DFP }-30)^{2}+\epsilon$ where PI is the plastochron index, DFP is the days from planting, $(3, \ldots 3$ are regression coefficients, and $\epsilon$ is normally distributed random error.

The coefficients of determination for this regression model ranged from 0.96 to 0.99 for the 10 genotype-environments. The quadratic term was significant in each case. The residual plots were no longer U-shaped, but some indicated increasing variance with time, a feature common to repeated measurement experiments. This violation of the underlying assumptions of regression analysis was not considered significant enough to warrant the added complexity of weighted least squares analysis. The addition of a cubic term did not improve the model.

General discussion. Use of PI for dictoyledonous species with compound leaves is relatively rare. In greenhouse conditions, Coleman and Greyson (1976) concluded that PI was applicable to tomato shoots during the vegetative stage of development, but not after flower bud production began at the vegetative apex. Handa and Yong Son (1974) found some significant deviations from the idealized leaf expansion patterns for six soybean plants

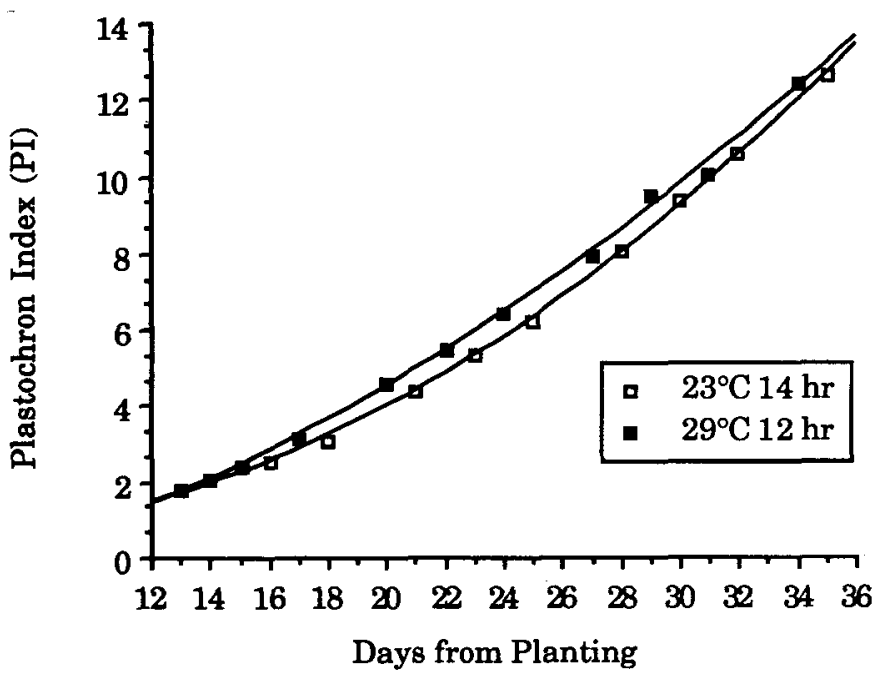

Fig. 3. Average plastochron indices (PI) of five bean genotypes grown at $23 \mathrm{C}$ with $14 \mathrm{hr}$ of daylength and 29C with $12 \mathrm{hr}$ of daylength. 
grown in a greenhouse. They concluded, however, that the deviations introduced insignificant effects upon the practical application of PI. Vendeland et al. (1982) concluded that the PI calculation was not suitable for soybean grown in the field under drought conditions.

The nature of the PI calculation implies uniform environmental conditions. Plants grown in fluctuating natural environments will never have uniform rates over time. The PI calculation, therefore, is most suitable for experimentation performed in a controlled, uniform environment. However, the PI concept may well be applicable to plants growing under a wide range of "conditions, where two PI measurements could be used to calculate an average rate of development over time.

The deviations in the PI calculation resulting from unequal expansion rates of successive leaves are minor because the associated error only infrequently affects the fractional component of the PI calculation. This study shows, however, that the rate of leaf initiation increased progressively during early growth. A similar pattern was observed in field-grown soybeans, but this deviation was dwarfed by the effect of drought stress and therefore did not receive further consideration (Vendeland et al., 1982). The increasing rate of leaf initiation complicates the use of PI in developmental studies over time. Rather than estimating the rate of plastochrons developed per unit time (slope) from two PI measurements, more measurements are needed to estimate a curvilinear function. Evaluation of experimental treatments are no longer simple comparisons between slopes, but rather complex comparisons between curvilinear functions (Yourstone and Wallace, 1990). Nevertheless, PI can still be a useful tool when nondestructive measurements of plant development in indeterminate bean are needed.

\section{Literature Cited}

Coleman, W.K. and R.I. Greyson. 1976. The growth and development of the leaf in tomato (Lycopersicon esculentum): I. The plastochron index, a suitable basis for description. Can. J. Bet. 54:2421-2428.

Erickson, R.O. and F.J. Michelini. 1957. The plastochron index. Amer. J. Bet. 44:297-304.

Handa, K. and S. Yong Son. 1974. On the expression of plant age of soybean by means of plastochron index. Proc. Crop Sci. Sot. Jpn. 43:8-28.

Lamoreaux, R. J., W.R. Chancy, and K.M. Brown. 1978. The plastochron index: A review after two decades of use. Amer. J. Bet. 65:586-593.

McCauley, M. and J. Croxdale. 1984. Establishment of a plastochron index for Dianthus chinensis L. Amer. J. Bet. 71:1373-1381.

Snedecor, G.W. and W.G. Cochran. 1980. Statistical methods. 7th ed. Iowa State Univ. Press, Ames.

Snyder, F.W. and J.A. Bunce. 1983. Use of the plastochron index to evaluate effects of light, temperature and nitrogen on growth of soya bean (Glycine max L. Merr.). Ann. Bet. 52:895-903.

Vendeland, J. S., T.R. Sinclair, S.C. Spaeth, and P.M. Cortes. 1982. Assumptions of plastochron index: Evaluation with soya bean under field drought conditions. Ann. Bet. 50:673-680.

Wallace, D.H. 1985. Physiological genetics of plant maturity, adaptation, and yield. Plant Breeding Rev. 3:21-167.

Watson, D.J. and E.C.D. Baptiste. 1938. A comparative physiological study of sugar-beet and marigold with respect to growth and sugar accumulation: I. Growth analysis of crop in the field. Ann. Bet. 2:437-480.

Yourstone, K.S. and D.H. Wallace. 1990. Effects of photoperiod and temperature on rate of node development in indeterminate bean. J. Amer. Soc. Hort. Sci. 115(5):824-828.

Zar, J.H. 1974, Biostatistical analysis. Prentice-Hall, Engleood Cliffs, N.J. 